\title{
REGENERATIVE TECHNOLOGIES IN THE COMPLEX TREATMENT OF PATIENTS WITH OSTEOCHONDRAL INJURIES OF THE ANKLE JOINT
}

\author{
O. Burianov ${ }^{1}$, L. Khimion ${ }^{2}$, T. Omelchenko ${ }^{1}$, V. Lianskorunskyi ${ }^{1}$
}

${ }^{1}$ Bogomolets National Medical University, Orthopedic and Traumatology, Kiev, Ukraine

${ }^{2}$ Shupyk National Medical Academy of Postgraduate Education, Family Medicine, Kiev, Ukraine

The clinical efficiency of regenerative technologies such as PRP, debridement, abrasive chondroplasty, microfracturing, drilling, osteochondral autotransplantation in the treatment of patients with osteochondral injuries and ankle defects was evaluated.

Methods: 36 patients aged from 21 to 67 years were treated. In 27 patients (group 1), the ankle arthroscopy was performed with the removal of free osteochondral bodies, debridement, tunneling or microfractioning in the affected area followed by the use of PRP (fig.1). In 9 patients (group 2), the above procedures were performed with arthrotomy and osteotomy of the medial malleolus and osteochondral autotransplantation was performed (fig.2). In the autotransplantation, the defect place was filled with PRP. The functional condition of the ankle was assessed by VAS and AOFAS before treatment, 3 and 12 months after treatment.

Results: In the group of arthroscopic treatment, after 3 months, the pain syndrome in VAS decreased from $6.4 \pm$ 0.4 to $2.3 \pm 0.3$, and after 12 months to $1.7 \pm 0.2$. According to AOFAS, the function of the joint increased from $35 \pm 5.4$ points to $73 \pm 4.7$ points in 3 months, and to $89 \pm 2.9$ in 12 months.
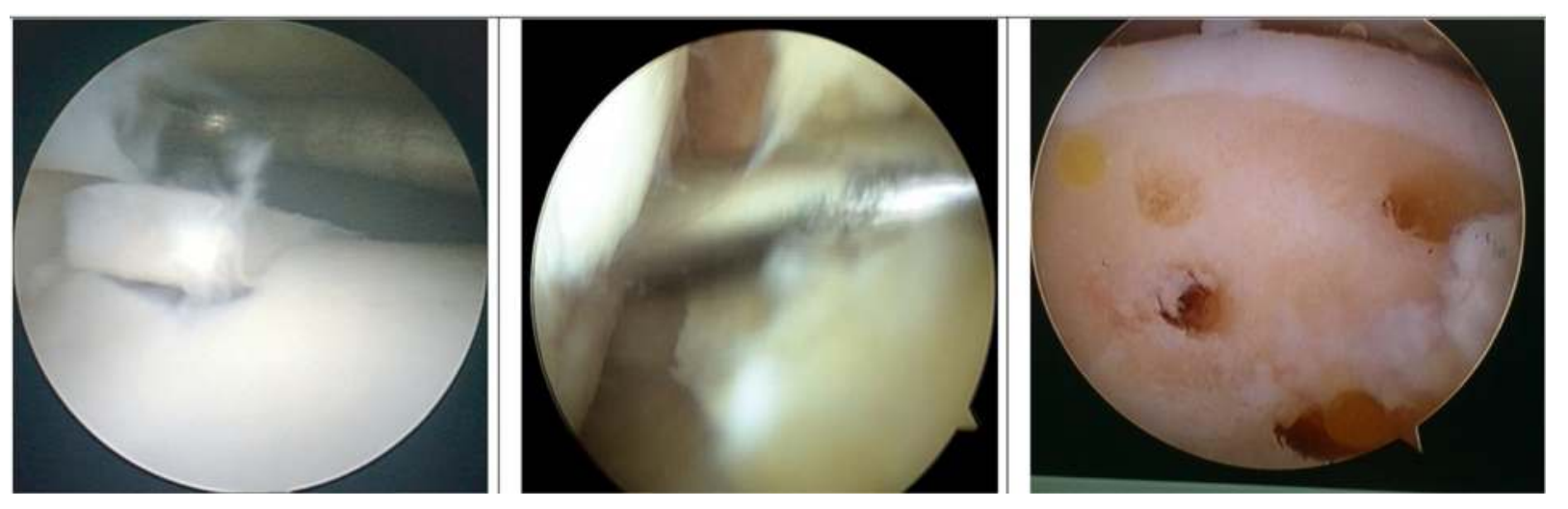

fig.1. Removing of free osteochondral bodies, debridement and tunneling in the affected area
In the group of patients with osteochondral autotransplantation, the pain with VAS before treatment was $8.1 \pm 0.6,3$ months after treatment, the pain syndrome decreased to 3.6 \pm 1.8 , and after 12 months to $2.1 \pm 0.3$. The joint function of AOFAS from $34 \pm 2.8$ points after 3 months increased to 67 \pm 4.1 , and after 12 months it was $83 \pm 2.9$ (table 1 ).

Conclusions: A differentiated approach to the choice of treatment tactics for patients with post-traumatic osteochondral ankle defects and the use of regenerative technologies in the system of treatment, allowed to obtain good results in the treatment of patients with minimal grade.

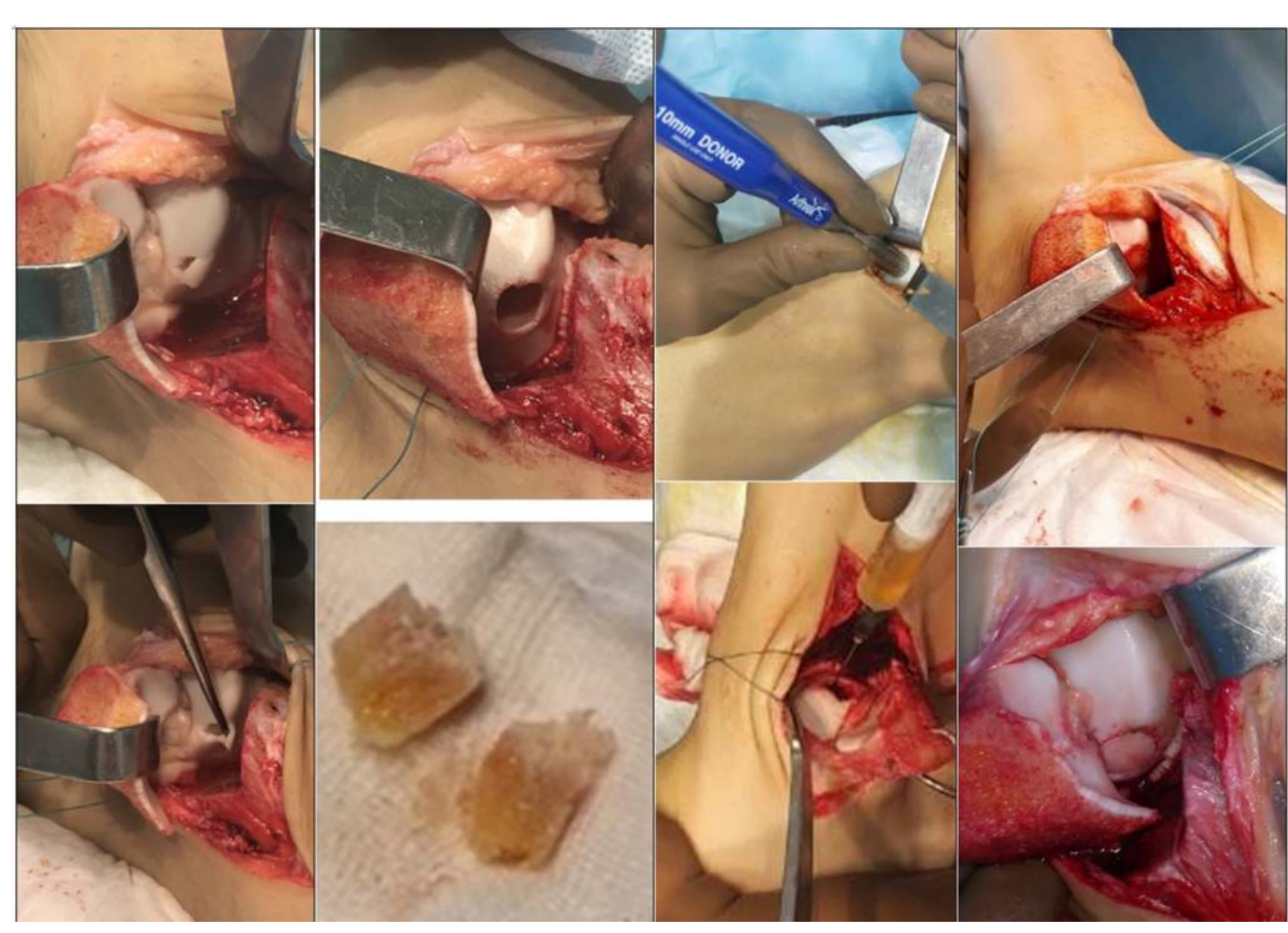

fig. 2 Arthrotomy, revision, debridement of the affected area and preparation for osteochondral autotransplantation, transplant fence, injection of PRP, closure of the defect

Table 1. Evaluation of treatment outcomes in clinical study groups

\begin{tabular}{|c|c|c|c|c|c|c|}
\hline $\begin{array}{l}\text { Group of pa- } \\
\text { tients, } n\end{array}$ & $\begin{array}{l}\text { System } \\
\text { evaluation } \\
\text { results }\end{array}$ & $\begin{array}{c}\text { Before } \\
\text { treatment } \\
(M \pm S D)\end{array}$ & 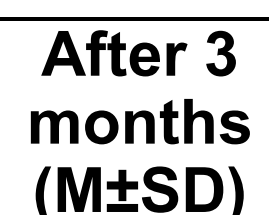 & $\mathbf{p}^{1}$ & 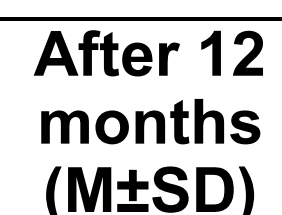 & $\mathbf{p}^{2}$ \\
\hline \multirow{2}{*}{$\begin{array}{l}\text { 1st group, } \\
\left(\mathrm{n}_{1}=27\right)\end{array}$} & VAS, points & $6,4 \pm 0,4$ & $2,3 \pm 0,3^{*}$ & $<0,01$ & $1,7 \pm 0,2^{* *}$ & $<0,05$ \\
\hline & AOFAS, points & $35 \pm 5,4$ & $73 \pm 4,7^{*}$ & $<0,01$ & $89 \pm 2,9^{*}$ & $<0,01$ \\
\hline \multirow{2}{*}{$\begin{array}{l}\text { 2nd group, } \\
\left(\mathrm{n}_{2}=9\right)\end{array}$} & VAS, points & $8,1 \pm 0,6$ & $3,6 \pm 1,8^{*}$ & $<0,01$ & $2,1 \pm 0,3^{*}$ & $<0,01$ \\
\hline & AOFAS, points & $34 \pm 2,8$ & $67 \pm 4,1^{*}$ & $<0,01$ & $83 \pm 2,9^{*}$ & $<0,01$ \\
\hline
\end{tabular}

1. Verhagen RA, Struijs PA, Bossuyt PM, van Dijk CN. Systematic review of treatment strategies for osteochondral defects of the talar dome. Foot Ankle Clin. 2003; 8:233-242. doi: 10.1016/S1083-7515(02)00064-5

2. Anders S, Lechler P, Rackl W, Grifka J, Schaumburger J. Fluoroscopy-guided retrograde core drilling and cancellous bone grafting in osteochondral defects of the talus. Int Orthop. 2012;36(8):1635-1640. doi: 10.1007/s00264-012-1530-9. 